\title{
Predicting activity coefficients with the DebyeHückel theory using concentration dependent static permittivity
}

Lei, Qun; Peng, Baoliang; Sun, Li; Luo, Jianhui; Chen, Yuan; Kontogeorgis, Georgios M.; Liang, Xiaodong

Published in:

AIChE Journal

Link to article, DOI:

10.1002/aic. 16651

Publication date:

2020

Document Version

Peer reviewed version

Link back to DTU Orbit

Citation $(A P A)$ :

Lei, Q., Peng, B., Sun, L., Luo, J., Chen, Y., Kontogeorgis, G. M., \& Liang, X. (2020). Predicting activity coefficients with the DebyeHückel theory using concentration dependent static permittivity. AlChE Journal, 66(11), [e16651]. https://doi.org/10.1002/aic.16651

\section{General rights}

Copyright and moral rights for the publications made accessible in the public portal are retained by the authors and/or other copyright owners and it is a condition of accessing publications that users recognise and abide by the legal requirements associated with these rights.

- Users may download and print one copy of any publication from the public portal for the purpose of private study or research.

- You may not further distribute the material or use it for any profit-making activity or commercial gain

- You may freely distribute the URL identifying the publication in the public portal 


\title{
Predicting activity coefficients with the Debye-Hückel
}

\section{theory using concentration dependent static}

\section{permittivity}

Qun Lei ${ }^{1}$, Baoliang Peng ${ }^{1,2, *}$, Li Sun ${ }^{3}$, Jianhui Luo ${ }^{1,2}$, Yuan Chen ${ }^{3}$, Georgios

\author{
M. Kontogeorgis ${ }^{3}$, and Xiaodong Liang ${ }^{3, *}$ \\ ${ }^{1}$ Research Institute of Petroleum Exploration \& Development (RIPED), \\ PetroChina, Beijing 100083, P. R. China \\ ${ }^{2}$ Key Laboratory of Nano Chemistry (KLNC), CNPC, Beijing 100083, P. R.
} China

${ }^{3}$ Center for Energy Resources Engineering, Department of Chemical and Biochemical Engineering, Technical University of Denmark, Kgs. Lyngby, 2800, Denmark

${ }^{*}$ Corresponding authors: pengbl@petrochina.com.cn, xlia@kt.dtu.dk

\section{Abstract}

In order to investigate the impacts of a concentration dependent static permittivity in the Debye-Hückel theory, two electrostatic Helmholtz free energy models and four activity coefficient models, with the ion-solvent interactions naturally included, are derived under different

This article has been accepted for publication and undergone full peer review but has not been through the copyediting, typesetting, pagination and proofreading process which may lead to differences between this version and the Version of Record. Please cite this article as doi: 10.1002/aic.16651 
assumptions. The effects of static permittivity and model parameters are analyzed by predicting the mean ionic activity coefficients. It is found out that it is reasonable to assume a constant static permittivity in deriving the electrostatic Helmholtz free energy model but it is highly recommended to take the concentration dependence of static permittivity into account in subsequent calculations of thermodynamic properties. The activity coefficient model derived in this way accurately predicts the mean ionic activity coefficients of the investigated systems up to $0.1 \mathrm{~mol} / \mathrm{kg} \mathrm{H} \mathrm{H}_{2} \mathrm{O}$, which indicates that the size parameters in the Debye-Hückel theory might be determined in advance before it is integrated into a more complete thermodynamic model.

\section{Introduction}

The Debye-Hückel theory ${ }^{1}$ is the first successful and probably the most widely used model for electrostatic interactions when describing an electrolyte solution, which is formed when electrolytes (e.g. salts) are dissolved into a polar solvent or solvent mixture and they dissociate into ions completely or partially. ${ }^{2-20}$ Water is the most common solvent in this category. Despite the fact that the theory was developed almost 100 years ago, both fundamental research on this theory and application-oriented studies using this theory have been actively conducted in recent years. ${ }^{21-31}$ An electrolyte solution behaves very different from a non-electrolyte one, as it starts to deviate very much from an ideal solution already at very low electrolyte concentrations, ${ }^{32}$ which was the main reason of the development of the Debye-Hückel theory. ${ }^{1,33}$ It is readily known from the references cited above that different modifications had been developed for the Debye-Hückel theory, most of which are, however, based on the extended Debye-Hückel law or the limiting law. ${ }^{18}$ This is possibly because, not until recently, ${ }^{34,35}$ the original version of the Debye-Hückel theory had not been revisited. With these contributions, it has become popular in using the original Debye-Hückel theory in thermodynamic models of the equation of state type. ${ }^{26-30,36-38}$ 
It has becoming accepted that a Born-type equation ${ }^{39}$ shall be included in order to describe the ion-solvent interactions when modeling an electrolyte solution, with either the DebyeHückel or the mean spherical approximation theory. ${ }^{22,23,29,37,40-48}$ It has been shown ${ }^{22,35}$ that a full version of the Debye-Hückel theory naturally contains a contribution for the ion-solvent interactions, which is essentially equivalent to the Born equation used in most of the aforementioned references. ${ }^{45}$ In this section, however, in order to distinguish these two different contributions, the Debye-Hückel theory is still used to only represent the ion-ion interactions, while the Born equation is used for the ion-solvent interactions. More details are presented and discussed in the following sections. The size parameters of ions are needed in both the Debye-Hückel theory and the Born equation. Even though the Debye-Hückel theory was derived in the size parameter of individual ions, which is called the distance of closest approach, it is common practice, also a misreading, ${ }^{35}$ to use an equal value for both cation and anion of a salt. It was 'discovered' by Zarubin and Pavlov ${ }^{25}$ why the theory is blind to the size dissimilarity, but it needs to be pointed out that this discovery was only based on the extended Debye-Hückel law, which did not take the ion-solvent interactions into account. There are discussions which size parameter shall be used in the Debye-Hückel theory and the Born equation. ${ }^{37,45,49,50}$ The same parameter was used in both contributions in some studies, ${ }^{22,35}$ and different size parameters were used in some other cases. ${ }^{29,45,51}$ Both the Debye-Hückel theory and the Born equation are using the so-called primitive approach, in which the solvent is considered a dielectric continuum, characterized by its static permittivity, usually also known as dielectric constant. In the original derivation of the Debye-Hückel theory, the static permittivity was assumed constant. A Gibbs/Helmholtz, not distinguished, ${ }^{33}$ free energy model was first obtained in the derivation and other thermodynamic properties, e.g. activity coefficients, could be derived via well-established thermodynamic relations. Since then most applications followed the same idea, especially the ones in the category of activity coefficient models. When the static permittivity is constant, the contribution from the Born equation to the activity coefficients is zero. The static 
permittivity is in principle a complex function of concentration due to the complicated interactions among solvent molecules and ions, e.g. the kinetic polarization deficiency, a debated topic, ${ }^{52,53}$ and the nonlocal dielectric response. ${ }^{54}$ In most applications, an empirical correlation of static permittivity is used. ${ }^{37}$ It is explicitly stated in the recent revisit ${ }^{35}$ that the composition, temperature and volume dependence of the static permittivity shall be taken into account after the Helmholtz free energy model has been derived under the assumption of a constant static permittivity. In this way, the ion-solvent interactions naturally comes into the theory. Maribo-Mogensen et al. ${ }^{55,56}$ developed a theoretically sound approach to calculate the static permittivity, which can be consistently integrated with the association equation of state models. There have also been some studies which considered a concentration dependent static permittivity in deriving the electrostatic Helmholtz free energy model. Hückel ${ }^{2}$ and Teitler et al. ${ }^{57}$ extended the Debye-Hückel theory by assuming a linear concentration-dependent static permittivity during the derivation, which was criticized by Gronwall et al. ${ }^{58}$ and Helgeson et al. ${ }^{12}$ According to Shilov and Lyashchenko, ${ }^{22}$ these studies were unfortunately ignored by the experts of the field. Very recently, therefore, Shilov and Lyashchenko $^{22}$ re-visited and presented an approach to take a more general concentration dependence of the static permittivity into account in deriving the free energy model, with the ion-solvent interactions included as well.

In order to investigate the effects of using a concentration dependent static permittivity in the Debye-Hückel theory, one unique feature of this work is to derive four existing activity coefficient models in the same framework, via Helmholtz free energy, and generalize them to use symbolically independent size parameters of individual ions. Moreover, to the best of our knowledge, it is the first time that the different extensions and the full version of the original Debye-Hückel theory are compared with each other using the same information of static permittivity. We focus ourselves in aqueous solutions, with water being the only solvent, of a single fully dissociated strong salt. Before systematically investigating the impacts of using a concentration dependent static permittivity in the theory, it is discussed the effects 


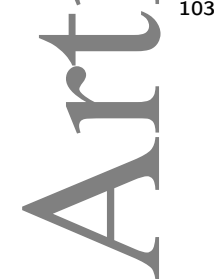

of size parameters in the theory. The same input information is used in all models and no parameters are adjusted. Conclusions are given in the end.

\section{Theory}

\section{The Debye-Hückel theory}

In the framework of the Debye-Hückel theory, the electrostatic contribution to the Helmholtz free energy consists of two terms, one from the ion-solvent interactions and the other from the interionic interactions. Following the partial charging process, ${ }^{33,35,59}$ it can be written

$$
\begin{aligned}
A^{\text {elec }} & =A^{\text {self }}+A^{D H} \\
& =\sum_{j} N_{j} \int_{0}^{z_{j} e} \frac{q_{j}}{4 \pi \varepsilon_{0} \varepsilon_{r}} \frac{1}{R_{j}} \mathrm{~d} q_{j}-\sum_{j} N_{j} \int_{0}^{z_{j} e} \frac{q_{j}}{4 \pi \varepsilon_{0} \varepsilon_{r}} \frac{\kappa}{1+\kappa d_{j}} \mathrm{~d} q_{j} \\
& =\sum_{j} N_{j} \int_{0}^{1} \frac{\lambda z_{j} e}{4 \pi \varepsilon_{0} \varepsilon_{r}} \frac{1}{R_{j}} z_{j} e \mathrm{~d} \lambda-\sum_{j} N_{j} \int_{0}^{1} \frac{\lambda z_{j} e}{4 \pi \varepsilon_{0} \varepsilon_{r}} \frac{\kappa}{1+\kappa d_{j}} z_{j} e \mathrm{~d} \lambda
\end{aligned}
$$

where $N_{j}, q_{j}, z_{j}, R_{j}$ and $d_{j}$ are the number, charge, valency (charge number), solvation radius, and the distance of closest approach of ion $j . e$ is the elementary charge, $\varepsilon_{0}$ is the vacuum permittivity, and $\varepsilon_{r}$ is the relative static permittivity of the solution. $\lambda$ is the charging process parameter, from 0 to $1 . \kappa$ is the inverse Debye screening length, defined by

$$
\kappa^{2}=\frac{1}{k_{B} T} \frac{1}{\varepsilon_{0} \varepsilon_{r}} \frac{1}{V} \sum_{j} N_{j} q_{j}^{2}=\frac{1}{k_{B} T} \frac{N_{A} e^{2}}{\varepsilon_{0} \varepsilon_{r}} \frac{1}{V} \sum_{j} n_{j} z_{j}^{2}
$$

where $k_{B}$ is the Boltzmann constant, $\mathrm{T}$ is the temperature, $\mathrm{V}$ is the total volume. $N_{A}$ is the Avogadro constant, $n_{j}$ is the number of moles of ion (or compound) $j$, apparently $N_{j}=N_{A} n_{j}$. The first term of equation (1) is known as self-energy ${ }^{35}$ or solvation contribution, ${ }^{22}$ which was not included in the original derivation of Debye and Hückel. ${ }^{1}$ If the discharging of ions in the vacuum is taken into account, it becomes the famous Born equation, ${ }^{39}$ in which way $R_{j}$ is often called Born radius. Hereafter, the two terms are respectively referred as the self 


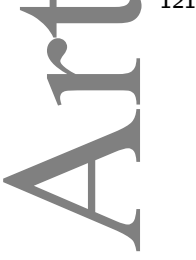

term and the DH term, as shown in equation (1). It is worth noticing that independent and individual size parameters of ions are symbolically used in both terms. It is common practice to assume the static permittivity of the solution constant during the partial charging process, while a very recent work ${ }^{22}$ reminded the possibility to include the concentration dependence under certain assumptions.

When the static permittivity of the solution is constant during the partial charging process, the self term is given by

$$
A^{\text {self }}=\frac{N_{A} e^{2}}{4 \pi \varepsilon_{0} \varepsilon_{r}} \sum_{j} \frac{n_{j} z_{j}^{2}}{2 R_{j}}
$$

And the DH term is obtained ${ }^{1}$

$$
\begin{aligned}
A^{D H} & =-\sum_{j} N_{j} \int_{0}^{1} \frac{\lambda z_{j} e}{4 \pi \epsilon_{0} \epsilon_{r}} \frac{\lambda \kappa}{1+\lambda \kappa d_{j}} z_{j} e \mathrm{~d} \lambda \\
& =-\sum_{j} \frac{N_{A} n_{j} z_{j}^{2} e^{2} \kappa}{4 \pi \varepsilon_{0} \varepsilon_{r}} \int_{0}^{1} \frac{\lambda^{2}}{1+\lambda \kappa d_{j}} \mathrm{~d} \lambda \\
& =-\frac{N_{A} e^{2}}{12 \pi \varepsilon_{0} \varepsilon_{r}} \sum_{j} n_{j} z_{j}^{2} \kappa\left\{\frac{3}{\left(\kappa d_{j}\right)^{3}}\left[\ln \left(1+\kappa d_{j}\right)-\kappa d_{j}+\frac{1}{2}\left(\kappa d_{j}\right)^{2}\right]\right\} \\
& =-\frac{N_{A} e^{2}}{12 \pi \varepsilon_{0} \varepsilon_{r}} \sum_{j} n_{j} z_{j}^{2} \kappa \chi_{j}
\end{aligned}
$$

where $\chi_{j}$ is an auxiliary variable of the expression given in braces.

Michelsen and Mollerup ${ }^{35}$ presented essentially the same equations (3) and (4) but with the same size parameters of ions in both the self term and the DH term. They further emphasized that $A^{\text {elec }}$ is only one contribution to the total Helmholtz free energy but not the excess Gibbs energy, and the integrations in equation (1) have to be made at constant temperature, volume and composition, so that the other contributions to the total Helmholtz free energy are not affected. After the electrostatic Helmholtz free energy model is derived, the dependence of the static permittivity on temperature, volume and composition has to be taken into account for subsequent calculations of thermodynamic properties. ${ }^{35}$ The electrostatic contribution to 
while the remaining parts are very similar.

It needs to be pointed out, on one hand, that the equations derived above present a generalized version of the work of Shilov and Lyashchenko, ${ }^{22}$ in which average (or common) size parameters of ions were used for both the self term and the DH term. On the other hand, the electrostatic contribution to the Helmholtz free energy is used instead of the Gibbs energy. Shilov and Lyashchenko ${ }^{22}$ pointed out that the partial molar volume related part in the conversion between Helmholtz free energy and Gibbs energy is small and can be neglected, and Debye $^{33}$ used these two thermodynamic functions effectively without distinguishing them, because the solution was considered incompressible. The same argument was adopted in a recent review. ${ }^{37}$

\section{Activity coefficient models}

Even though it has been a misreading since the original article, as emphasized in Michelsen and Mollerup, ${ }^{35}$ it is common practice to compare the predictions from the Debye-Hückel theory to the experimental activity coefficients. ${ }^{622,25,45}$ This practice is followed in this work, as the main purpose is to compare the various models derived from and to evaluate the various impact factors in the Debye-Hückel theory. Traditionally, the infinitely diluted solution is chosen as the reference state for ions, in which way the activity coefficient of an ion is obtained

$$
\begin{aligned}
\ln \gamma_{i} & =\frac{1}{R T}\left[\left(\frac{\partial A^{\text {elec }}}{\partial n_{i}}\right)_{T, V, n_{j}}-\left(\frac{\partial A^{\text {elec }}}{\partial n_{i}}\right)_{T, V, n_{j}, n_{i} \rightarrow 0}\right] \\
& =\ln \gamma_{i}^{\text {self }}+\ln \gamma_{i}^{D H}
\end{aligned}
$$

where $R$ is the gas constant, and $\gamma_{i}$ is the activity coefficient of ion $i$.

Equation (21) is written in terms of an individual ion, for which Zarubin and Pavlov ${ }^{25}$ argued that this is a serious limitation due to the violation of electrical neutrality. We believe, however, that it is conceptually feasible and mathematically more grounded to have activity coefficients written in individual ions, and it shall be easier and more flexible to be extended 
to multi-salt solutions as well.

Hereafter the activity coefficient model with a combination of equations (6) and (7) in equation (21) is called DHFULL, which represents the full version of the original Debye-Hückel theory. The activity coefficient model with a combination of equations (17) and (19) in equation (21) is named EDH2015, representing the extended Debye-Hückel theory developed by Shilov and Lyashchenko ${ }^{22}$ in 2015.

When the explicit derivative of the relative static permittivity with respect to the number of moles is ignored, i.e. the second term in equation (6) and the first term in equation (7), the contribution of the self term to the activity coefficients reads

$$
\ln \gamma_{i}^{\text {self }}=\frac{e^{2}}{4 \pi k_{B} T \varepsilon_{0}} \frac{z_{i}^{2}}{2 R_{i}}\left(\frac{1}{\varepsilon_{r}}-\frac{1}{\varepsilon_{w}}\right)
$$

This is the same one as the Born equation and used in literature. ${ }^{44,45,60}$

The contribution of the DH term to the activity coefficients follows

$$
\frac{1}{R T}\left(\frac{\partial A^{D H}}{\partial n_{i}}\right)_{T, V, n_{l}}=-\frac{e^{2}}{24 \pi k_{B} T \varepsilon_{0} \varepsilon_{r}} \kappa z_{i}^{2}\left[2 \chi_{i}+\frac{1}{\sum_{l} n_{l} z_{l}^{2}} \sum_{j} n_{j} z_{j}^{2} \sigma_{j}\right]
$$

The same equation has been given in Breil et al. ${ }^{61}$

When an average distance of closest approach $\left(d_{ \pm}\right)$is used for all ions, it can be reformulated into the following famous form ${ }^{18,33,62}$

$$
\ln \gamma_{i}^{D H}=-\frac{e^{2}}{8 \pi k_{B} T \varepsilon_{0} \varepsilon_{r}} \frac{\kappa}{1+\kappa d_{ \pm}} z_{i}^{2}=-\frac{A \sqrt{I}}{1+B d_{ \pm} \sqrt{I}} z_{i}^{2}
$$

where $I$ is the ionic strength, and $A$ and $B$ are two auxiliary coefficients given by

$$
I=1000\left(\frac{1}{2} \sum_{j} c_{j} z_{j}^{2}\right)
$$




$$
\begin{aligned}
& A=\left(2 \pi N_{A}\right)^{1 / 2}\left(\frac{e^{2}}{4 \pi k_{B} T \varepsilon_{0} \varepsilon_{r}}\right)^{3 / 2} \\
& B=\left(\frac{2 N_{A} e^{2}}{k_{B} T \varepsilon_{0} \varepsilon_{r}}\right)^{1 / 2}
\end{aligned}
$$

201
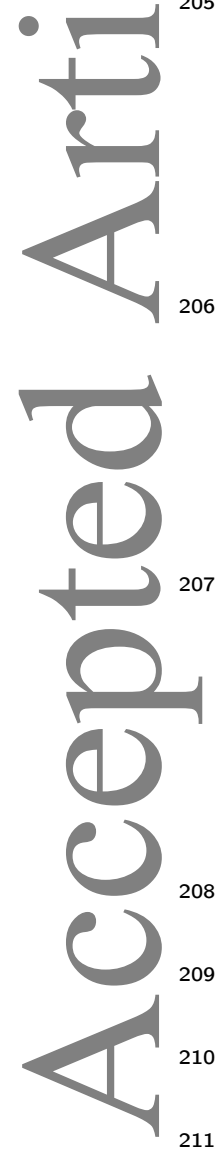

212

where $c_{j}$ is the molar concentration (molarity) of ion $j$, defined by $c_{j}=n_{j} / 1000 \mathrm{~V}(\mathrm{~mol} / L)$.

Hereafter the activity coefficient model with a combination of equations (22) and (24) in equation (21) is called EDH, representing the traditional extended Debye-Hückel law.

By assuming that the volume of ions is zero, Fowler and Guggenheim ${ }^{4}$ converted equation (24) in terms of molality to

$$
\ln \gamma_{i}^{D H}=-\frac{A_{m} \sqrt{I_{m}}}{1+B_{m} d_{ \pm} \sqrt{I_{m}}} z_{i}^{2}
$$

The molal ionic strength $I_{m}$, and the coefficients $A_{m}$ and $B_{m}$ are accordingly given by

$$
\begin{gathered}
I_{m}=\frac{1}{2} \sum_{j} m_{j} z_{j}^{2} \\
A_{m}=\left(2 \pi N_{A} \rho_{w}\right)^{1 / 2}\left(\frac{e^{2}}{4 \pi k_{B} T \varepsilon_{0} \varepsilon_{r}}\right)^{3 / 2} \\
B_{m}=\left(\frac{2 N_{A} e^{2} \rho_{w}}{k_{B} T \varepsilon_{0} \varepsilon_{r}}\right)^{1 / 2}
\end{gathered}
$$

where $m_{j}$ is the molality of ion $j$, and $\rho_{w}$ is the density of water at the given temperature.

Hereafter the activity coefficient model with a combination of equations (22) and (27) in equation (21) is called EDH-M, representing the traditional extended Debye-Hückel law expressed in terms of molality. For summary and easy reference, the derivations of the activity coefficient models are illustrated in Figure 1. 
213

For a single salt solution, it can be reorganized into

$$
c=\frac{k_{B} T}{1000 \sum_{j} \nu_{j} z_{j}^{2}} \frac{\varepsilon_{0}}{N_{A} e^{2}} \varepsilon_{w} \kappa_{w}^{2}=\Omega \varepsilon_{w} \kappa_{w}^{2}
$$

where $c$ is the molar concentration of the salt, $\nu_{j}$ is the stoichiometric coefficient of ion $j$ in the salt, and $\Omega$ is merely an auxiliary variable.

During the partial charging process, it becomes

$$
c=\Omega \varepsilon_{w}\left(\lambda \kappa_{w}\right)^{2}
$$

221 When the relative static permittivity of the solution is given, e.g. by a correlation,

$$
\varepsilon_{r}(c)=\varepsilon_{w}+a_{1} c+a_{2} c^{3 / 2}+a_{3} c^{2}+a_{4} c^{5 / 2}
$$

where $a_{1}, a_{2}, a_{3}$ and $a_{4}$ are correlation coefficients (constants).

The function $f$ in equation (12) is then calculated from

$$
f\left(\lambda k_{w}\right)=\frac{\varepsilon_{r}(c)}{\varepsilon_{w}}
$$

Therefore,

$$
f^{\prime}\left(\lambda k_{w}\right)=\frac{1}{\varepsilon_{w}} \frac{\partial \varepsilon_{r}}{\partial c} \frac{\partial c}{\partial\left(\lambda \kappa_{w}\right)}
$$


Following the works of Shilov and Lyashchenko ${ }^{22}$ and Boda et al., ${ }^{44,45,60}$ the correlations of relative static permittivity and the size parameters of ions studied in this work are listed in Table 1 and Table 2 , respectively. $d_{j}$ is the distance of closest approach of ion $j$, equal to two times of its Pauling radius, ${ }^{63}$ and $d_{ \pm}$is the average distance of closest approach of the cation and the anion of a given salt, so it can be considered a salt-specific parameter. $R_{j}$ is the Born radius of ion $j$, taken from Julianna et al., ${ }^{44}$ and $R_{ \pm}$is, similar to $d_{ \pm}$, the average Born radius. In this work, only single salt solutions are considered, which means, according to Shilov and Lyashchenko, ${ }^{22}$

$$
\begin{aligned}
d_{ \pm} & =\frac{1}{2}\left(d_{+}+d_{-}\right) \\
R_{ \pm} & =\frac{1}{2}\left(R_{+}+R_{-}\right)
\end{aligned}
$$

where $d_{+}$and $d_{-}$are $d_{j}$ of cation and anion, and $R_{+}$and $R_{-}$are $R_{j}$ of cation and anion, respectively. The mean ionic activity coefficient of a salt is given by

$$
\ln \gamma_{ \pm}=\frac{1}{\nu_{+}+\nu_{-}}\left(\nu_{+} \ln \gamma_{+}+\nu_{-} \ln \gamma_{-}\right)
$$

where $\nu_{+}$and $\nu_{-}$are stoichiometric coefficients of cation and anion, respectively.

It is common that the molal mean ionic activity coefficient $\left(\gamma_{ \pm}^{m}\right)$ is reported in literature, and they are related via

$$
\gamma_{ \pm}=\gamma_{ \pm}^{m}\left[1+\left(\nu_{+}+\nu_{-}\right) m M_{\mathrm{H}_{2} \mathrm{O}}\right]
$$

where $m$ is the molality of the salt $\left(\mathrm{mol} / \mathrm{kg} \mathrm{H} \mathrm{H}_{2} \mathrm{O}\right)$ and $M_{\mathrm{H}_{2} \mathrm{O}}$ is the molecular weight of water $(\mathrm{kg} / \mathrm{mol})$.

The correlations of density from Novotný et al. ${ }^{64}$ have been used for water as well as in converting molar concentration $(c)$ and molality $(m)$ of aqueous salt solutions in this work. 


\section{Results and discussion}

The three activity coefficient models, EDH2015, EDH and EDH-M, are compared for predicting the mean ionic activity coefficients of $\mathrm{NaCl}, \mathrm{LiCl}$ and $\mathrm{CaCl}_{2}$ at $298.15 \mathrm{~K}$ in Figure 2, in which average size parameters of ions are used in both the self term and the DH term. It is traditional practice, also more physically consistent, to use the static permittivity of water in equation (24) of EDH and equation (27) of EDH-M, which was also the case in one comparison reported by Shilov and Lyashchenko. ${ }^{22}$ In this work, however, the assumptions made for model derivation are relaxed, and the same correlation of static permittivty is used in all three models for each salt, for which the results from EDH and EDH-M are indicated by $\left(\varepsilon_{r}\right)$ in the legend. The predictions from EDH using the static permittivity of water are also added in Figure 2 and denoted by $\operatorname{EDH}\left(\varepsilon_{w}\right)$. It is readily seen that $\operatorname{EDH}\left(\varepsilon_{w}\right)$ presents much smaller predictions, because the contribution from the self term, equation (22), disappears due to a concentration independent static permittivity, as pointed out in the Introduction. EDH-M $\left(\varepsilon_{r}\right)$ gives very similar but slightly smaller values, somewhat closer to the experimental data, depending on the concentration and the system. Moreover, it is surprising to see that $\mathrm{EDH}\left(\varepsilon_{r}\right)$ predicts exactly the same results as EDH2015, as the concentration dependence of static permittivity is ignored in the integration during the partial charging process as well as in the calculation of the derivatives with respect to the number of moles, as illustrated in Figure 1. For a clearer visualization, the results of EDH $\left(\varepsilon_{r}\right)$ are plotted by points, and they will be denoted by EDH only, i.e. without $\left(\varepsilon_{r}\right)$, in the following text.

Regarding the use of individual or average size parameters of ions in the self term, several approaches have been investigated in the literature. Shilov and Lyashchenko ${ }^{22}$ used average size parameters in both the self term and the DH term when they presented EDH2015, while

Boda and co-workers suggested using an individual size parameter in the self term. ${ }^{44,45,60}$ In a following study, Shilov and Lyashchenko ${ }^{50}$ discovered that this suggestion in general failed to predict experimental data for alkali metal iodide solutions. Three combinations of using an individual or average size parameter in EDH2015 are compared in Figure 3 for 
predicting the mean ionic activity coefficients. It is readily seen that the size parameters show significant effects on the results. Individual size parameters in both the self term and the $\mathrm{DH}$ term give the best results for $\mathrm{NaCl}$, average size parameters in both the self term and the $\mathrm{DH}$ term present the best results for $\mathrm{LiCl}$, and a combination of an individual size parameter in the self term and an average size parameter in the DH term shows the best results for $\mathrm{CaCl}_{2}$. In terms of quantitative results, therefore, it is hard to make a conclusion which size parameters shall be used. It is worth noticing that using average size parameters EDH2015 always predicts larger values than using individual size parameters. Even though Zarubin and Pavlov ${ }^{25}$ discovered that the average size parameter gave the best fitting to the mean ionic activity coefficients, it has to be pointed out that the fitting was based on the DH term only in their work. Michelsen and Mollerup ${ }^{35}$ pointed out that it has been a common misreading that the Debye-Hückel theory is restricted to ions of equal distance of closest approach. Simonin ${ }^{48}$ indicated that it is a more restrictive approach to use individual size parameters. Moreover, it has been shown in the Theory section that it is possible to derive the models using individual size parameters, and we believe that it is more rigorous as well as more flexible, especially when extending to multi-salt systems, to use individual size parameters in both terms. Therefore, individual size parameters will be used in the following investigations.

Figure 4 presents the predictions of the mean ionic activity coefficients from EDH2015, EDH and DHFULL with individual size parameters in both the self term and the DH term. On one hand, DHFULL always predicts larger mean ionic activity coefficients than EDH2015 and EDH. It is hard to conclude, however, if EDH2015 is better than DHFULL, because EDH2015 and DHFULL respectively perform better in $\mathrm{NaCl}$ and $\mathrm{LiCl}$, while they show equally good performance on $\mathrm{CaCl}_{2}$, over a wide range of molality. It can be readily seen, on the other hand, that EDH2015 and EDH again give the same results, independent on which size parameters are used. However, the fact that EDH2015 and EDH predict the same mean ionic activity coefficients does not necessarily imply that their terms give the same 
contributions to the activity coefficients of individual ions. Figures 5a and 5b respectively show the contributions of the self term and the DH term to the activity coefficients. The results of the salt are plotted in points for a clearer visualization. It has been proved by Valiskó and Boda ${ }^{45}$ that the self term in EDH2015 gives the same contribution to the mean ionic activity coefficients as equation (22) but gives slightly larger values for the bigger ion and slightly smaller values for the smaller ion. This observation is verified in Figure 5a, but it needs to be pointed out that in this case the differences of the self term in these two models are noticeable for the contribution to the activity coefficients of single ions. Figure 5b presents the same analysis for the DH term. The DH term in EDH2015 predicts smaller values for the bigger ion and larger values for the smaller ion than that of EDH. In this way, they give the same contributions to the mean ionic activity coefficients. We believe that these results are due to the assumptions made in equations (9) and (12), which were neither explained in detail nor justified in the original literature. ${ }^{22}$ These assumptions led to the relationship between the molar concentration $(c)$ and the charging process parameter $(\lambda)$ in equation (32), which was not reported in the original literature ${ }^{22}$ but in our opinion is a rather strong assumption. It would be of importance in future works to investigate whether these assumptions can be justified or not, especially theoretically, besides merely comparing with experimental data of some systems with selected parameters. It could be suggested that EDH may replace EDH2015 as long as the mean ionic activity coefficients are the only concern, e.g. for engineering phase equilibrium calculations with the activity coefficient models, and it even offers more flexibility, e.g. for multi-salt systems. It can be readily seen from Figure 5 that the self term and the DH term in DHFULL respectively predict larger and smaller activity coefficients of single ions as well as of the salt than those of EDH2015, which firstly imply that the second term in equation (5) plays a significant role. Moreover, the fact that DHFULL always predicts larger values than EDH2015 as shown in Figure 4 indicate that the second term in equation (5) has a more pronounced impact on the self term. 
340

Different correlations of the relative static permittivity have been used by different researchers ${ }^{22,60}$ for the aqueous solution of $\mathrm{NaCl}$. Originally, Boda and co-workers ${ }^{44}$ used the correlation $\mathrm{Na}-\mathrm{C} 1$, and later they switched to another correlation $\mathrm{Na}-\mathrm{C} 2$, with a weaker concentration dependence, because it was believed more reasonable. ${ }^{60}$ Figure 6 presents the mean ionic activity coefficients of $\mathrm{NaCl}$ predicted from EDH2015 and DHFULL with the two correlations listed in Table 1 . There is no doubt that the static permittivity plays a significant role in both EDH2015 and DHFULL. It is known from Boda and co-workers ${ }^{60}$ that the correlation Na-C2 gives larger static permittivity, so Figure 6 shows that the larger the static permittivity is used the smaller the activity coefficients are, and the difference of these two correlations becomes more pronounced as the solution gets concentrated.

Even though the predictions from these models have been compared to the experimental mean ionic activity coefficients over a wide range of concentration and good performance might be obtained with carefully chosen input information, it has to be emphasized that equation (21) is in principle only valid for dilute solutions. When the electrolyte solution gets concentrated, other contributions, e.g. volume exclusion and short-range interactions, shall be taken into account. Figure 7 presents a further comparison of EDH2015 and DHFULL in the low concentration region. It can be seen that the predictions from EDH2015 and DHFULL diverge from each other around $m=0.01 \mathrm{~mol} / \mathrm{kg} \mathrm{H}_{2} \mathrm{O}$. Up to $m=0.1 \mathrm{~mol} / \mathrm{kg} \mathrm{H}_{2} \mathrm{O}$, EDH2015 and DHFULL present equally good predictions for the mean ionic activity coefficients of $\mathrm{NaCl}$ using both correlations. It is worth noticing that the differences of these two correlations are more pronounced with DHFULL than with EDH2015. DHFULL gives better predictions for $\mathrm{LiCl}$ and $\mathrm{CaCl}_{2}$. More importantly, DHFULL predicts reasonably accurate mean ionic activity coefficients up to $m=0.1 \mathrm{~mol} / \mathrm{kg} \mathrm{H}_{2} \mathrm{O}$ for $\mathrm{NaCl}$ and $m=0.2 \mathrm{~mol} / \mathrm{kg} \mathrm{H}_{2} \mathrm{O}$ for $\mathrm{LiCl}$ and $\mathrm{CaCl}_{2}$. It is usually believed that the traditional Debye-Hückel theory (EDH $\left.\left(\varepsilon_{w}\right)\right)$ can describe the activity coefficients for dilute solutions only, e.g. $m=0.01 \mathrm{~mol} / \mathrm{kg} \mathrm{H}_{2} \mathrm{O}$ for $\mathrm{NaCl}$ using the paramters given in this work. When the concentration dependence of static permittivity is taken into account, as derived and discussed above, the Debye-Hückel 
theory naturally contains the ion-solvent interactions. This may have extended the application limit of the theory. Moreover, the extension may have been even more pronounced when the Born radii are adjusted to the Gibbs energy of solvation, ${ }^{48,60}$ and an adjustable parameter in the self term is supported by a recent in-depth analysis of the Born equation. ${ }^{48}$ The results indicate that it is reasonable to assume a constant static permittivity during the partial charging process to derive the electrostatic Helmholtz free energy model, and then to relax this assumption in the subsequent property calculations. ${ }^{35}$ In this way, DHFULL still presents a thermodynamically consistent approach, and it can be integrated into a thermodynamic model, e.g. an equation of state, ${ }^{29}$ with other molecular interactions considered. The integrated model shall then offer the capability to describe various experimental data over a wide range of temperature, pressure and concentration. ${ }^{30,38,49,51,65,66}$ It also provides the flexibility to adjust the size parameters together with other model parameters to the experimental data if this becomes necessary.

\section{Conclusion}

In this work, the electrostatic Helmholtz free energy from the original Debye-Hückel theory is derived by assuming a composition independent static permittivity. It is recommended that the temperature, volume and composition dependence of the static permittivity is taken into account in the subsequent calculations of thermodynamic properties. This model is denoted as DHFULL, representing the full version of the original Debye-Hückel theory, with the ionsolvent interactions included. If the concentration dependence of the static permittivity is further ignored and the ions are assumed having the same distance of closest approach in deriving the electrostatic activity coefficient model, the traditional extended Debye-Hückel law can be built, and it is called EDH. An extension of the Debye-Hückel theory developed in 2015, with a concentration dependent static permittivity in deriving the electrostatic Helmholtz free energy model, is generalized using individual size parameters of ions, and it 
is denoted as EDH2015.

EDH2015 and EDH always give the same mean ionic activity coefficients, and DHFULL predicts larger values than the other two models, as long as the same input information is used. In terms of quantitative results compared with the experimental mean ionic activity coefficients, it is hard to conclude which model presents the best results over a wide range of concentration, because the predictions are significantly affected by the size parameters and the static permittivity. Individual size parameters are recommended in DHFULL for a straightforward, consistent and flexible extension to multi-salt solutions, which is a limitation of EDH2015 in its current form. We also believe that the activity coefficients predicted from the Debye-Hückel theory shall not be compared to the experimental data of concentrated solutions, in which contributions from other molecular forces must be taken into account. DHFULL has shown accurate predictions for the mean ionic activity coefficients up to $0.1 \mathrm{~mol} / \mathrm{kg} \mathrm{H}_{2} \mathrm{O}$, in which region other forces except those considered in the DebyeHückel theory might be neglected for ions for the investigated systems. This tells that it might be reasonable to determine the size parameters in the Debye-Hückel theory in advance before it is integrated into a more complete thermodynamic model, while the picture might be changed when other properties, e.g. density, also become important to describe.

\section{Acknowledgements}

The authors wish to thank the European Research Council (ERC) for funding of this research under the European Union's Horizon 2020 research and innovation program (grant agreement No 832460), ERC Advanced Grant project "New Paradigm in Electrolyte Thermodynamics". This research is jointly supported by PetroChina Scientific Research and Technology Development Project (2018A-0907), Scientific Research and Technology Development Project of RIPED, PetroChina (YGJ2019-11-01), PetroChina Research Institute of Petroleum Exploration and Development (19HT00001023), and the State Scholarship Fund 
of China Scholarship Council (No. 201608320224).

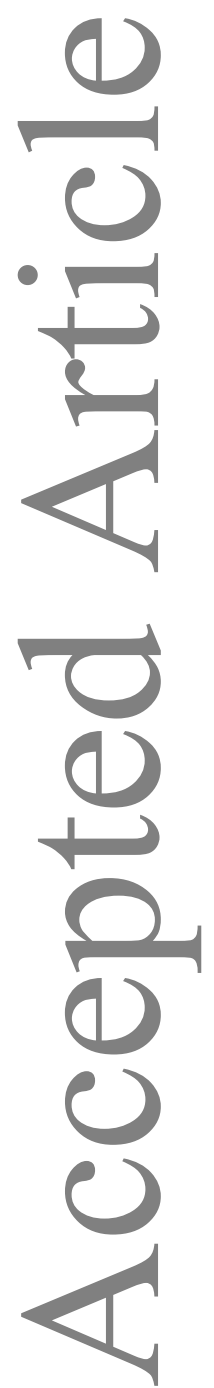


401

411

\section{References}

[1] Debye P, Hückel E. Zur theorie der elektrolyte. I. Gefrierpunktserniedrigung und verwandte erscheinunge (The theory of electrolytes. I. Lowering of freezing point and related phenomena). Physikalische Zeitschrift. 1923;24:185-206.

[2] Hückel E. Zur theorie konzentrierterer wässeriger Lösungen starker elektrolyte. Physikalische Zeitschrift. 1925;26:93-147.

[3] Onsager L. Theories of Concentrated Electrolytes. Chemical Reviews. 1933;13(1):73-89.

[4] Fowler SRH, Guggenheim EA. Statistical thermodynamics: a version of statistical mechanics for students of physics and chemistry. Cambridge: Cambridge University Press, 1939.

[5] Debye PJW. The Collected Papers of Peter J. W. Debye. New York-London: Interscience, 1954.

[6] Robinson RA, Stokes RH. Electrolyte Solutions (2nd Revised Edition). Dover Publications, 1959.

[7] Guggenheim EA. The accurate numerical solution of the Poisson-Boltzmann equation. Trans Faraday Soc. 1959;55:1714-1724.

[8] Bromley LA. Thermodynamic properties of strong electrolytes in aqueous solutions. AIChE Journal. 1973;19(2):313-320.

[9] Pitzer KS. Thermodynamics of electrolytes. I. Theoretical basis and general equations. The Journal of Physical Chemistry. 1973;77(2):268-277.

[10] Pitzer KS. Electrolytes. From dilute solutions to fused salts. Journal of the American Chemical Society. 1980;102(9):2902-2906. 
[11] Pitzer KS, Simonson JM. Thermodynamics of multicomponent, miscible, ionic systems: theory and equations. The Journal of Physical Chemistry. 1986;90(13):3005-3009.

[12] Helgeson HC, Kirkham DH, Flowers GC. Theoretical prediction of the thermodynamic behavior of aqueous electrolytes by high pressures and temperatures; IV, Calculation of activity coefficients, osmotic coefficients, and apparent molal and standard and relative partial molal properties to 600 degrees $\mathrm{C}$ and 5kb. American Journal of Science. 1981;281(10):1249-1516.

[13] Chen CC, Britt HI, Boston J, Evans L. Local composition model for excess Gibbs energy of electrolyte systems. Part I: Single solvent, single completely dissociated electrolyte systems. AIChE Journal. 1982;28(4):588-596.

[14] Chen CC, Evans LB. A local composition model for the excess Gibbs energy of aqueous electrolyte systems. AIChE Journal. 1986;32(3):444-454.

[15] Sander B, Rasmussen P, Fredenslund A. Calculation of solid-liquid equilibria in aqueous solutions of nitrate salts using an extended UNIQUAC equation. Chemical Engineering Science. 1986;41(5):1197-1202.

[16] Zemaitis Jr JF, Clark DM, Rafal M, C SN. Handbook of Aqueous Electrolyte Thermodynamics:Theory and Application. New York: John Wiley \& Sons, Ltd, 1986.

[17] Thomsen K. Aqueous Electrolytes Model Parameters and Process Simulation. PhD thesis, Technical University of Denmark, 1997.

[18] Thomsen K. Electrolyte Solutions: Thermodynamics, Crystallization, Separation methods. Technical University of Denmark, 2009.

[19] Kontogeorgis GM, Folas GK. Thermodynamic models for industrial applications: from classical and advanced mixing rules to association theories. John Wiley \& Sons, Ltd, 2009. 
[20] von Stockar U, van der Wielen LAM. Biothermodynamics: The Role of Thermodynamics in Biochemical Engineering. CRC Press, 2013.

[21] Fraenkel D. Simplified electrostatic model for the thermodynamic excess potentials of binary strong electrolyte solutions with size-dissimilar ions. Molecular Physics. 2010;108(11):1435-1466.

[22] Shilov IY, Lyashchenko AK. The Role of Concentration Dependent Static Permittivity of Electrolyte Solutions in the Debye-Hückel Theory. The Journal of Physical Chemistry B. 2015;119(31):10087-10095.

[23] Schlumpberger S, Bazant MZ, Simple Theory of Ionic Activity in Concentrated Electrolytes, 2017.

[24] Liu JL, Li CL. A generalized Debye-Hückel theory of electrolyte solutions. AIP Advances. 2019;9(1):015214.

[25] Zarubin DP, Pavlov AN. A closer look at the Debye-Hückel theory and its modification in the SiS model of electrolyte solutions. Molecular Physics. 2019;0(0):1-13.

[26] Cameretti LF, Sadowski G, Mollerup JM. Modeling of Aqueous Electrolyte Solutions with Perturbed-Chain Statistical Associated Fluid Theory. Industrial \& Engineering Chemistry Research. 2005;44(9):3355-3362.

[27] Held C, Sadowski G, Carneiro A, Rodríguez O, Macedo EA. Modeling thermodynamic properties of aqueous single-solute and multi-solute sugar solutions with PC-SAFT. AIChE Journal. 2013;59(12):4794-4805.

[28] Held C, Reschke T, Mohammad S, Luza A, Sadowski G. ePC-SAFT revised. Chemical Engineering Research and Design. 2014;92(12):2884-2897.

[29] Maribo-Mogensen B, Thomsen K, Kontogeorgis GM. An electrolyte CPA equation of state for mixed solvent electrolytes. AIChE Journal. 2015;61(9):2933-2950. 
[30] Shahriari R, Dehghani MR. Prediction of thermodynamic properties of aqueous electrolyte solutions using equation of state. AIChE Journal. 2017;63(11):5083-5097.

[31] Tanveer S, Chen CC. A comprehensive thermodynamic model for high salinity produced waters. AIChE Journal. 2020;66(1):e16818.

[32] Lewis GN, Randall M. THE ACTIVITY COEFFICIENT OF STRONG ELECTROLYTES.1. Journal of the American Chemical Society. 1921;43(5):1112-1154.

[33] Debye P. Osmotische Zustandsgleichung und Aktivität verdünnter starker Elektrolyte. Physikalische Zeitschrift. 1924;25:97-107.

[34] Breil M. Thermodynamics, Experimental, and Modelling of Aqueous Electrolyte and Amino Acid Solutions. PhD thesis, Technical University of Denmark, 2001.

[35] Michelsen ML, Mollerup JM. Thermodynamic Models: Fundamentals \& Computational Aspects. Holte: Tie-Line Publications, 2007.

[36] Lin Y. Development of an equation of state for solution containing electrolytes. PhD thesis, Technical University of Denmark, 2007.

[37] Kontogeorgis G, Maribo-Mogensen B, Thomsen K. The Debye-Hückel theory and its importance in modeling electrolyte solutions. Fluid Phase Equilibria. 2018;462:130-152.

[38] Bülow M, Ji X, Held C. Incorporating a concentration-dependent dielectric constant into ePC-SAFT. An application to binary mixtures containing ionic liquids. Fluid Phase Equilibria. 2019;492:26-33.

[39] Born M. Volumen und hydratationswärme der ionen. Zeitschrift für Physik A Hadrons and Nuclei. 1920;1(1):45-48.

[40] Wu J, Prausnitz JM. Phase Equilibria for Systems Containing Hydrocarbons, Water, and Salt: An Extended Peng-Robinson Equation of State. Industrial \& Engineering Chemistry Research. 1998;37(5):1634-1643. 
[41] Myers JA, Sandler SI, Wood RH. An Equation of State for Electrolyte Solutions Covering Wide Ranges of Temperature, Pressure, and Composition. Industrial \& Engineering Chemistry Research. 2002;41(13):3282-3297.

[42] Inchekel R, de Hemptinne JC, Fürst W. The simultaneous representation of dielectric constant, volume and activity coefficients using an electrolyte equation of state. Fluid Phase Equilibria. 2008;271(1):19-27.

[43] Eriksen DK, Lazarou G, Galindo A, Jackson G, Adjiman CS, Haslam AJ. Development of intermolecular potential models for electrolyte solutions using an electrolyte SAFTVR Mie equation of state. Molecular Physics. 2016;114(18):2724-2749.

[44] Vincze J, Valiskó M, Boda D. The nonmonotonic concentration dependence of the mean activity coefficient of electrolytes is a result of a balance between solvation and ion-ion correlations. The Journal of Chemical Physics. 2010;133(15):154507.

[45] Valiskó M, Boda D. Comment on "The Role of Concentration Dependent Static Permittivity of Electrolyte Solutions in the Debye-Hückel Theory". The Journal of Physical Chemistry B. 2015;119(44):14332-14336.

[46] Schreckenberg JMA, Dufal S, Haslam AJ, Adjiman CS, Jackson G, Galindo A. Modelling of the thermodynamic and solvation properties of electrolyte solutions with the statistical associating fluid theory for potentials of variable range. Molecular Physics. 2014;112(17):2339-2364.

[47] Ahmed S, Ferrando N, de Hemptinne JC, Simonin JP, Bernard O, Baudouin O. Modeling of mixed-solvent electrolyte systems. Fluid Phase Equilibria. 2018;459:138-157.

[48] Simonin JP. On the "Born" term used in thermodynamic models for electrolytes. The Journal of Chemical Physics. 2019;150(24):244503. 
[49] Maribo-Mogensen B. Development of an Electrolyte CPA Equation of state for Applications in the Petroleum and Chemical Industries. PhD thesis, Technical University of Denmark, 2014.

[50] Shilov IY, Lyashchenko AK. Modeling activity coefficients in alkali iodide aqueous solutions using the extended Debye-Hückel theory. Journal of Molecular Liquids. 2017;240:172-178.

[51] Schlaikjer A, Thomsen K, Kontogeorgis G. eCPA: An ion-specific approach to parametrization. Fluid Phase Equilibria. 2018;470:176-187.

[52] Hubbard JB, Onsager L, van Beek WM, Mandel M. Kinetic polarization deficiency in electrolyte solutions. Proceedings of the National Academy of Sciences. 1977;74(2):401404.

[53] Chandra A, Wei D, Patey GN. Dielectric relaxation of electrolyte solutions: Is there really a kinetic dielectric decrement? The Journal of Chemical Physics. 1993;98(6):49594966.

[54] Levy A, Bazant M, Kornyshev A. Ionic activity in concentrated electrolytes: Solvent structure effect revisited. Chemical Physics Letters. 2020;738:136915.

[55] Maribo-Mogensen B, Kontogeorgis GM, Thomsen K. Modeling of Dielectric Properties of Complex Fluids with an Equation of State. The Journal of Physical Chemistry B. 2013;117(12):3389-3397.

[56] Maribo-Mogensen B, Kontogeorgis GM, Thomsen K. Modeling of Dielectric Properties of Aqueous Salt Solutions with an Equation of State. The Journal of Physical Chemistry B. 2013;117(36):10523-10533.

[57] Teitler S, Ginsburg N. Debye-Hückel Theory and the Concentration Dependent Dielectric Constant. The Journal of Chemical Physics. 1956;25(4):783-784. 
552

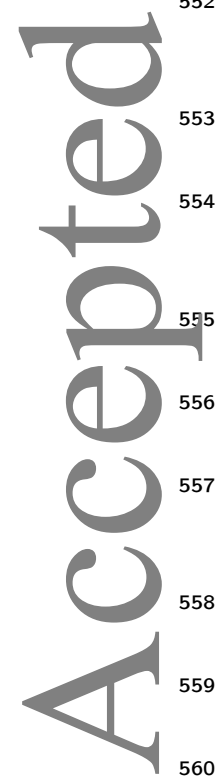

[58] Gronwall TH, Lamer VK. On the extension of the Debye-Hückel theory of strong electrolytes to concentrated solutions. Science. 1926;64(1648):122-122.

[59] McQuarrie DA. Statistical Mechanics. New York: Harper \& Row, 1976.

[60] Valiskó M, Boda D. The effect of concentration- and temperature-dependent dielectric constant on the activity coefficient of $\mathrm{NaCl}$ electrolyte solutions. The Journal of Chemical Physics. 2014;140(23):234508.

[61] Breil MP, Mollerup JM. The McMillan-Mayer framework and the theory of electrolyte solutions. Fluid Phase Equilibria. 2006;242(2):129-135.

[62] Debye P. Over ionen en hun activiteit. Chemisch Weekblad. 1923;20:562-568.

[63] Pauling L. The sizes of ions and the structure of ionic crystals. Journal of the American Chemical Society. 1927;49(3):765-790.

[64] Novotny P, Sohnel O. Densities of binary aqueous solutions of 306 inorganic substances. Journal of Chemical \& Engineering Data. 1988;33(1):49-55.

[65] Sun L, Liang X, von Solms N, Kontogeorgis GM. Modeling Tetra-n-butyl ammonium halides aqueous solutions with the electrolyte cubic plus association equation of state. Fluid Phase Equilibria. 2019;486:37-47.

[66] Sun L, Kontogeorgis GM, von Solms N, Liang X. Modeling of Gas Solubility Using the Electrolyte Cubic Plus Association Equation of State. Industrial \& Engineering Chemistry Research. 2019;58(37):17555-17567.

[67] Clarke ECW, Glew DN. Evaluation of the Thermodynamic Functions for Aqueous Sodium Chloride from Equilibrium and Calorimetric Measurements below $154^{\circ} \mathrm{C}$. Journal of Physical and Chemical Reference Data. 1985;14(2):489-610. 
- 57.
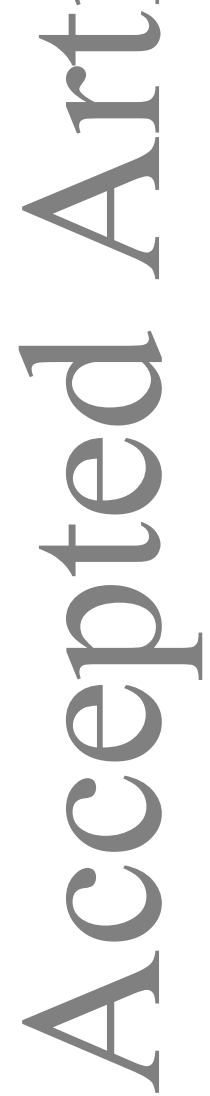

[68] Hamer WJ, Wu Y. Osmotic Coefficients and Mean Activity Coefficients of Uni-univalent Electrolytes in Water at $25154^{\circ} \mathrm{C}$. Journal of Physical and Chemical Reference Data. 1972;1(4):1047-1100.

[69] Staples BR, Nuttall RL. The activity and osmotic coefficients of aqueous calcium chloride at 298.15 K. Journal of Physical and Chemical Reference Data. 1977;6(2):385-408.

[70] Tikanen AC, Fawcett WR. Application of the mean spherical approximation and ion association to describe the activity coefficients of aqueous 1:1 electrolytes. Journal of Electroanalytical Chemistry. 1997;439(1):107-113. 


\section{List of Figures}

1 Illustration of the derivation process of the activity coefficient models. Green and Blue texts are used to distinguish the free energy models and the activity coefficient models, while Red texts are used for the different assumptions during the derivation process of different models. DHFULL denotes the full version of the original Debye-Hückel theory, ${ }^{1,35} \mathrm{EDH}$ and EDH-M represent the traditional extended Debye-Hückel law with molar concentration ${ }^{18,62}$ and molality $(\mathrm{M})^{4}$ for the ionic strength, respectively, while EDH2015 is for the model developed by Shilov and Lyashchenko ${ }^{22}$ in 2015 but generalized to be able to use individual size parameters of ions. . . . . . . . . . . . .

2 Comparison of the three models EDH2015, EDH and EDH-M for the mean ionic activity coefficients of (a) $\mathrm{NaCl}$, (b) $\mathrm{LiCl}$ and (c) $\mathrm{CaCl}_{2}$. The experimental data are taken from Clarke et al. ${ }^{67}$ for $\mathrm{NaCl}$, Hamer et al. ${ }^{68}$ for $\mathrm{LiCl}$ and Staples et al. ${ }^{69}$ for $\mathrm{CaCl}_{2}$. The average size parameters (Table 2) are used in all cases. The first correlation (Na-C1, Table 1) of the relative static permittivity is used for the aqueous solution of $\mathrm{NaCl}$. . . . . . . . . . .

3 The effect of using the individual or average size parameters of ions in the self term and the DH term. The results are shown using EDH2015 for (a) NaCl, (b) $\mathrm{LiCl}$ and (c) $\mathrm{CaCl}_{2}$. The first correlation (Na-C1, Table 1) of the relative static permittivity is used for the aqueous solution of $\mathrm{NaCl}$. . . . . . . .

4 Mean ionic activity coefficients of (a) $\mathrm{NaCl}$, (b) $\mathrm{LiCl}$ and (c) $\mathrm{CaCl}_{2}$ from EDH2015, EDH and DHFULL. The results from EDH are plotted in points for a clearer visualization. The first correlation (Na-C1, Table 1) of the relative static permittivity is used for the aqueous solution of $\mathrm{NaCl}$. . . . . . . . .

5 Comparisons of (a) the self term and (b) the DH term of EDH2015, EDH and DHFULL for the aqueous solution of $\mathrm{LiCl}$. The points represent the calculated results of the salt for a clearer visualization. . . . . . . . . . . . . . . 
$6 \quad$ The effect of using different correlations of the relative static permittivity (see Table 1) in EDH2015 and DHFULL for the aqueous solution of $\mathrm{NaCl}$. . . . . 44

7 Mean ionic activity coefficients of (a) $\mathrm{NaCl}$, (b) $\mathrm{LiCl}$ and (c) $\mathrm{CaCl}_{2}$ in the low concentration region from EDH2015 and DHFULL. . . . . . . . . . . 


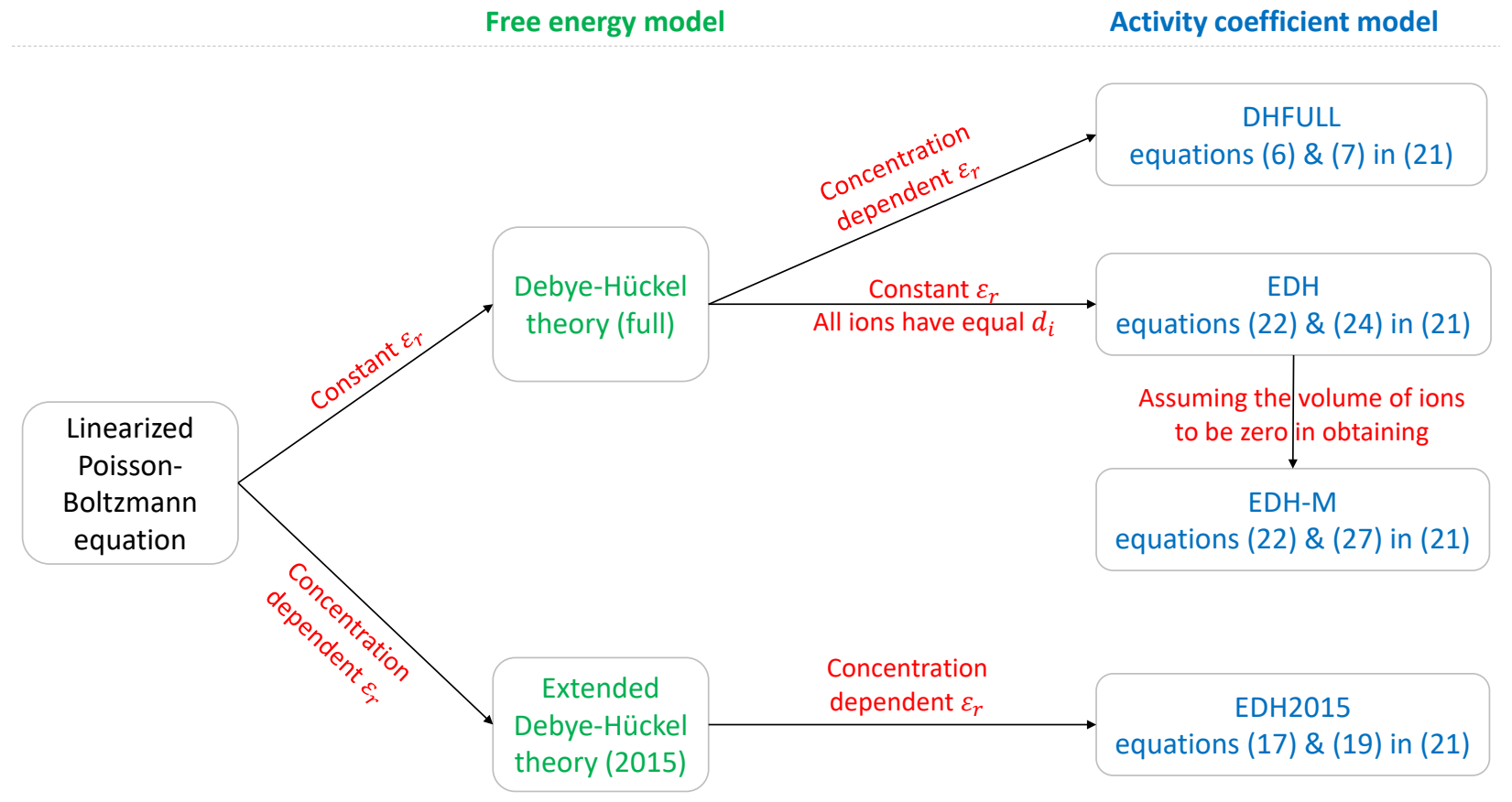

Figure 1: Illustration of the derivation process of the activity coefficient models. Green and Blue texts are used to distinguish the free energy models and the activity coefficient models, while Red texts are used for the different assumptions during the derivation process of different models. DHFULL denotes the full version of the original Debye-Hückel theory, ${ }^{1,35}$ EDH and EDH-M represent the traditional extended Debye-Hückel law with molar concentration ${ }^{18,62}$ and molality $(\mathrm{M})^{4}$ for the ionic strength, respectively, while EDH2015 is for the model developed by Shilov and Lyashchenko ${ }^{22}$ in 2015 but generalized to be able to use individual size parameters of ions. 


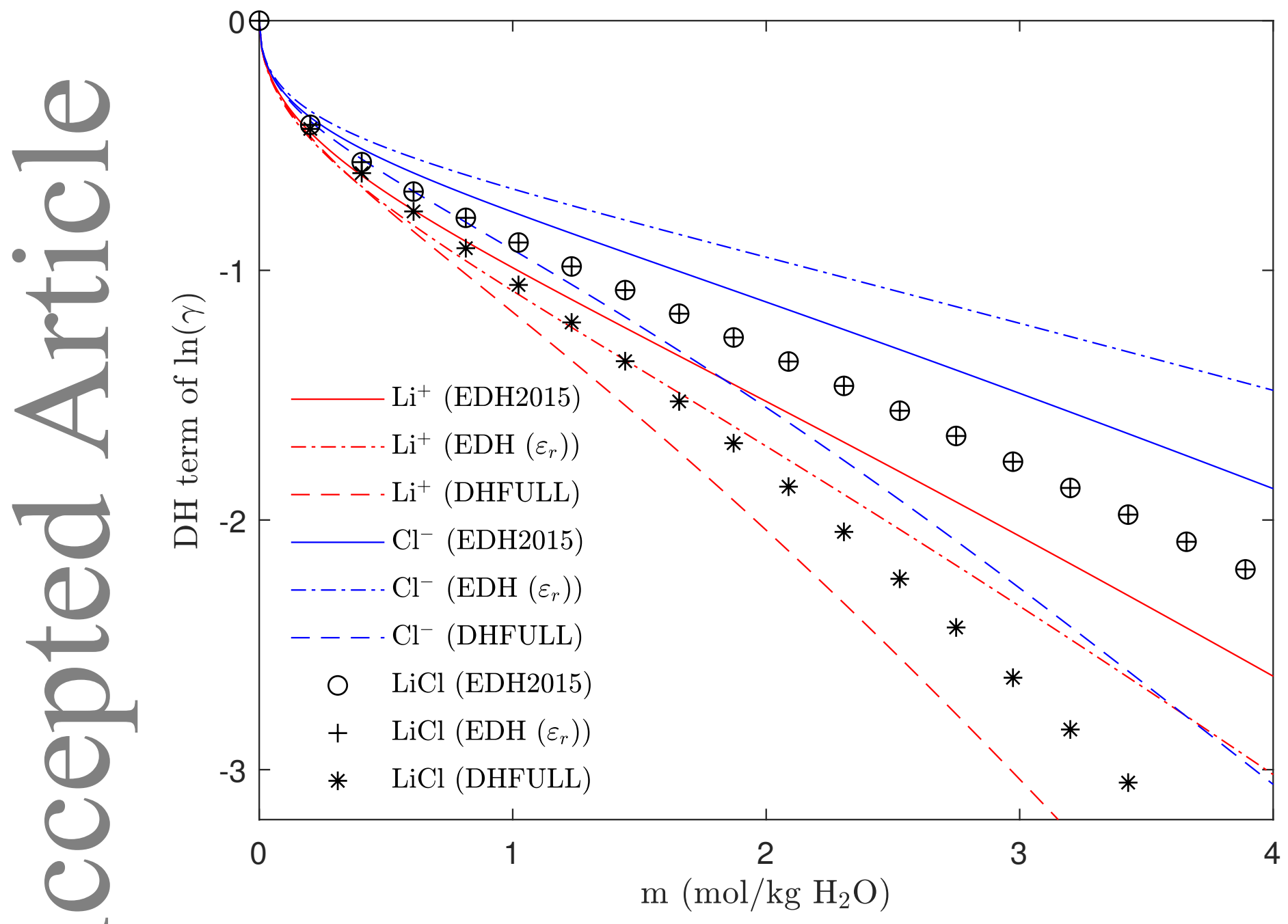

(b) DH term

Figure 5: Comparisons of (a) the self term and (b) the DH term of EDH2015, EDH and DHFULL for the aqueous solution of $\mathrm{LiCl}$. The points represent the calculated results of the salt for a clearer visualization. 


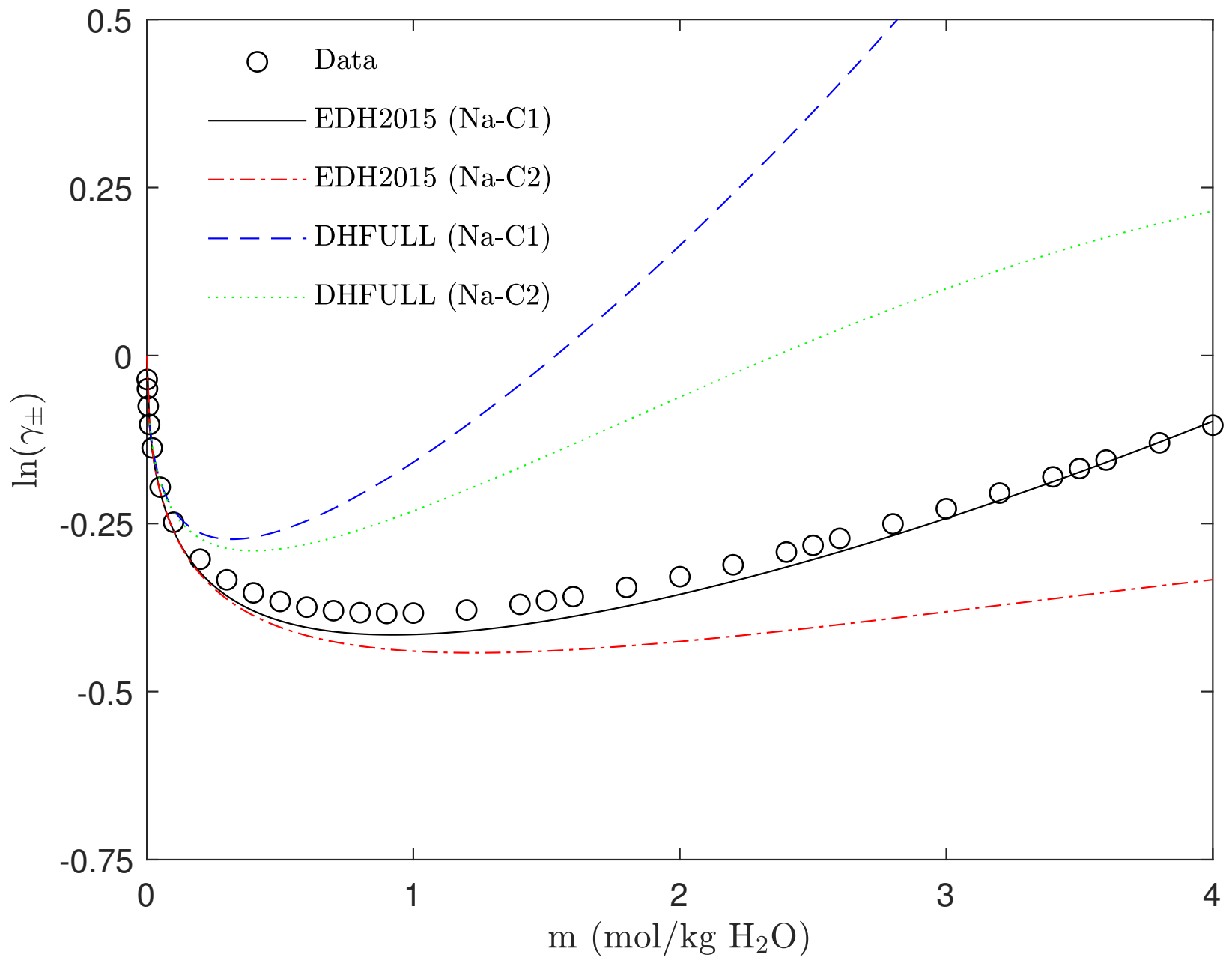

Figure 6: The effect of using different correlations of the relative static permittivity (see Table 1) in EDH2015 and DHFULL for the aqueous solution of $\mathrm{NaCl}$. 

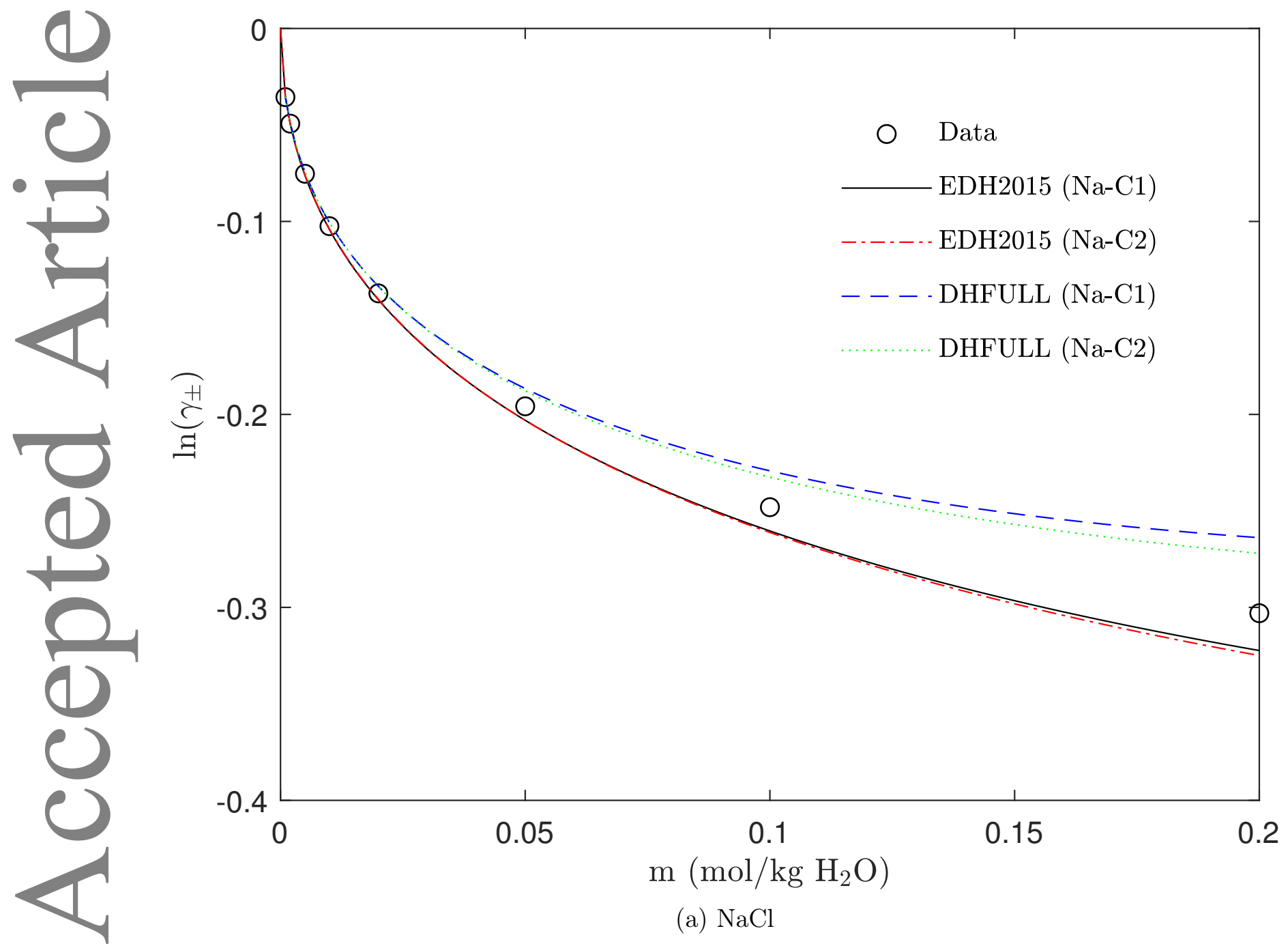

(a) $\mathrm{NaCl}$ 

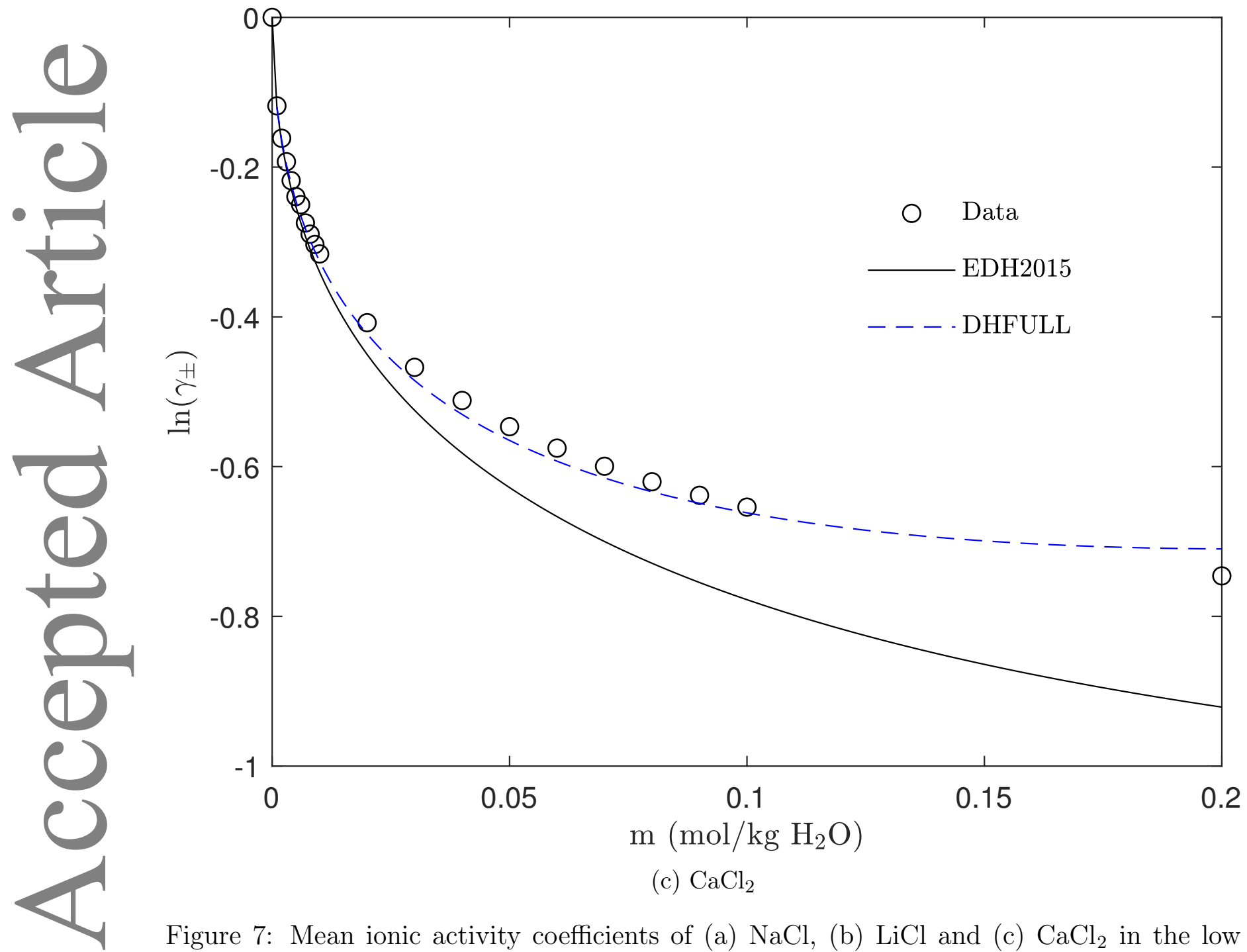

(c) $\mathrm{CaCl}_{2}$

Figure 7: Mean ionic activity coefficients of (a) $\mathrm{NaCl}$, (b) $\mathrm{LiCl}$ and (c) $\mathrm{CaCl}_{2}$ in the low concentration region from EDH2015 and DHFULL. 


\section{${ }_{603}$ List of Tables}

$604 \quad 1$ Correlations of the relative static permittivity . . . . . . . . . . . . . . . 49

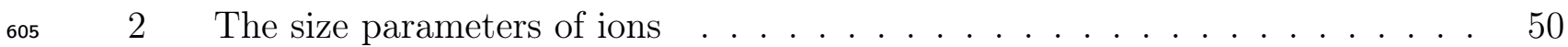

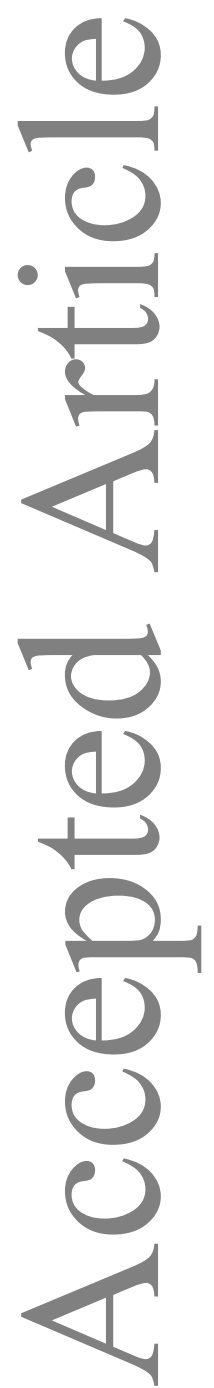


Table 1: Correlations of the relative static permittivity

\begin{tabular}{c|l|l|l}
\hline Salt & \multicolumn{1}{|c|}{ Correlation } & Notation & \multicolumn{1}{c}{ Ref } \\
\hline $\mathrm{NaCl}$ & $\varepsilon_{r}=78.4-16.2 c+3.1 c^{3 / 2}$ & Na-C1 & $22,44,70$ \\
$\mathrm{NaCl}$ & $\varepsilon_{r}=78.65-15.45 c+3.76 c^{3 / 2}$ & Na-C2 & 45 \\
$\mathrm{LiCl}$ & $\varepsilon_{r}=78.4-15.5 c+1.96 c^{2}-0.306 c^{5 / 2}$ & Li-C1 & 22,70 \\
$\mathrm{CaCl}_{2}$ & $\varepsilon_{r}=78.65-34 c+10 c^{3 / 2}$ & $\mathrm{Ca}-\mathrm{C} 1$ & 45 \\
\hline
\end{tabular}


Table 2: The size parameters of ions

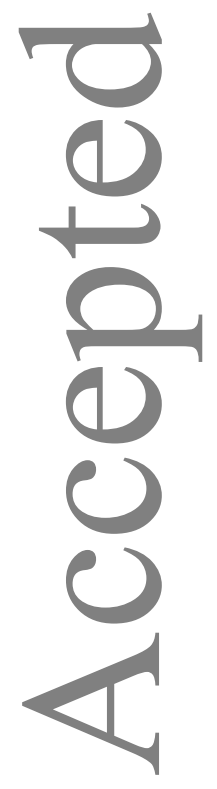

\begin{tabular}{c|c|c|c|c|l}
\hline Ion & $\mathrm{d}_{j}\left(10^{-10} \mathrm{~m}\right)$ & $\mathrm{d}_{ \pm}\left(10^{-10} \mathrm{~m}\right)$ & $\mathrm{R}_{j}\left(10^{-10} \mathrm{~m}\right)$ & $\mathrm{R}_{ \pm}\left(10^{-10} \mathrm{~m}\right)$ & \multicolumn{1}{c}{ Ref } \\
\hline $\mathrm{Na}^{+} / \mathrm{Cl}^{-}$ & $1.90 / 3.26$ & 2.76 & $1.62 / 2.26$ & 1.38 & 22,70 \\
$\mathrm{Li}^{+} / \mathrm{Cl}^{-}$ & $1.20 / 3.26$ & 2.41 & $1.30 / 2.26$ & 1.205 & 44 \\
$\mathrm{Ca}^{2+} / \mathrm{Cl}^{-}$ & $1.98 / 3.26$ & 2.80 & $1.71 / 2.26$ & 1.40 & 44 \\
\hline
\end{tabular}

